\title{
BMJ Open Effects of birth weight and growth on childhood wheezing disorders: findings from the Born in Bradford Cohort
}

\author{
Teumzghi F Mebrahtu, Richard G Feltbower, Roger C Parslow
}

To cite: Mebrahtu TF, Feltbower RG, Parslow RC Effects of birth weight and growth on childhood wheezing disorders: findings from the Born in Bradford Cohort. BMJ Open 2015;5: e009553. doi:10.1136/ bmjopen-2015-009553

- Prepublication history and additional material is available. To view please visit the journal (http://dx.doi.org/ 10.1136/bmjopen-2015009553)

Received 28 July 2015 Revised 23 October 2015 Accepted 26 October 2015

CrossMark

Division of Epidemiology and Biostatistics, School of Medicine, University of Leeds, Leeds, UK

Correspondence to Teumzghi F Mebrahtu; mt09tfm@leeds.ac.uk

\section{ABSTRACT}

Objectives: To examine the effects of birth weight and childhood growth on childhood wheezing disorders. We hypothesised that low birth weight and fast growth during early age would increase the risk of wheezing disorders.

Setting: Observational secondary analysis of data from the Born in Bradford cohort.

Participants: All children who were born at the Bradford Royal Infirmary hospital between March 2007 and December 2010 were eligible for the study. A total of 13734 and 1598 children participated in the analyses of the effects of birth weight and growth on wheezing disorders, respectively.

Primary and secondary outcome measures: Wheezing disorders diagnosis (diagnosed as asthma or had wheezing symptom) during the ages of 0 7 years were the primary outcome measures. Diagnosis of asthma and occurrence of wheezing during the same period were secondary outcome measures. Birth weight was classified as normal $(2.5-4.0 \mathrm{~kg})$, low $(<2.5 \mathrm{~kg})$ and high $(>4.0 \mathrm{~kg})$. Growth mixture models were used to drive growth pattern outcomes which were classified as 'normal', 'fast' and 'slow' growth based on their velocities between birth and 36 months.

Results: The adjusted relative risks (RRs) of wheezing disorders diagnosis for the low and high birthweight children were $1.29(95 \% \mathrm{Cl} 1.12$ to $1.50 ; p=0.001)$ and $0.91(95 \% \mathrm{Cl} 0.79$ to $1.04 ; \mathrm{p}=0.17$ ), respectively. The adjusted RRs of wheezing disorders diagnosis were $1.30(95 \% \mathrm{Cl} 0.56$ to $3.06 ; \mathrm{p}=0.54)$ and $0.60(95 \% \mathrm{Cl}$ 0.16 to 2.18; $p=0.44$ ), respectively, for the 'fast' and 'slow' growth as compared with the 'normal' growth.

Conclusions: Low birth weight is associated with an increased risk of wheezing disorders; however, there is a weak evidence that suggests high birthweight children have a reduced risk in this birth cohort. Low birth weight coupled with a slower growth until 3 months and a sharp growth between 3 and 12 months has an increased risk of wheezing disorders diagnosis.

\section{INTRODUCTION}

Asthma is defined as a chronic disease of the passage of airways, characterised by smooth muscle contraction, accumulation of mucous

\section{Strengths and limitations of this study}

- A large sample, contemporary birth cohort data were used.

- Direct Acyclic Graphs (DAGs) were used to minimise potential bias due to confounding.

- Multiple imputation by chained equations was used to minimise bias due to missing data.

- Age-specific and sex-specific standardised scores and growth percentiles were used to illustrate the growth of cohort children in reference to standard growth charts.

- Selection of participants was not random.

- Number of individuals in some of the growth classes was small, so the risk estimates were not robust.

- There was a substantial missing growth data at some follow-up periods, although missing data estimation models were used to minimise bias.

- Information on potential confounding (ie, family asthma and breast feeding) was missing.

and debris in the lumen, vascular congestion and airway wall oedema which leads to breathlessness and wheezing. ${ }^{1}$ Although it is claimed to be the most common childhood disease, ${ }^{2}$ there is, however, a lack of consistency in its diagnosis in clinical practice. ${ }^{3}$ This is due to the difficulty in diagnosing asthma in children, especially those of preschool age, in whom wheezing, which is the main symptom for asthma, can be caused by other illnesses. ${ }^{4}$ In addition, although there are various asthma confirmatory tests available, ${ }^{5}$ young children can be less cooperative in participating in such tests leading to an underdiagnosis of true asthma cases. Therefore, the word 'asthma' may not be an adequate term for what can be described as a spectrum of respiratory problems. As a result, some researchers have tended to use more inclusive terms such as 'wheezing disorders'. ${ }^{6-9}$

The effect of birth weight on wheezing disorders has been studied extensively with 
more than 40 observational epidemiological studies carried out to date. In our recent meta-analysis and systematic review of these studies, we reported that low birthweight children $(<2.5 \mathrm{~kg}$ ) have a $60 \%$ (OR $1.60 ; 95 \%$ CI 1.39 to 1.85$)$ and $37 \%(\mathrm{OR}=1.37 ; 95 \%$ CI 1.05 to 1.79$)$ higher risk of wheezing disorders when compared with $\geq 2.5$ and $2.5-4.0 \mathrm{~kg}$ birthweight children, respectively. ${ }^{10}$ We also found a modest increased risk in high birthweight children $(>4 \mathrm{~kg})$ when compared with normal birthweight $(2.5-4.0 \mathrm{~kg})$ children (OR 1.02; 95\% CI 0.99 to 1.04$)$. However, we acknowledged there was substantial heterogeneity among the low birthweight risk estimates which was not accounted for by study characteristics.

The effect of early childhood growth on wheezing disorders has not been widely studied. Results from a handful of previous studies are inconsistent with some suggesting fast growth predisposes to wheezing disorders ${ }^{11-20}$ and others reporting reduced risk of wheezing disorders. ${ }^{19}{ }^{21-23}$ In addition to that, all of these studies, with the exception of one, ${ }^{18}$ assumed homogeneous growth among children, either used statistical techniques that can now be improved on or a non-standard growth data analysis that makes comparison and replication of results very difficult. For example, three ${ }^{11} 1620$ used data-driven standardised scores (SDS), three $\begin{array}{lll}12 & 1922 & 23 \\ \text { used country-specific SDS and another }\end{array}$ one ${ }^{14}$ used non-standardised weight measurements.

The aim of the study was twofold: (1) further investigation of the effects of birth weight on wheezing disorders; and (2) investigation of the effects of early growth on wheezing disorders using a birth cohort data.

\section{METHODS}

Study participants

The Born in Bradford (BiB) study is a prospective, mainly biethnic, cohort that examines the impact of environmental, genetic and social factors on health of the population of Bradford. ${ }^{24}$ The methods of recruitment are explained in detail elsewhere. ${ }^{24}{ }^{25}$ In brief: recruitment of participants started in March 2007 and ended in December 2010; a total of 13776 pregnant mothers were recruited that resulted in 13857 births. Out of the total births, 123 died before the age of 1 week which resulted in a total of 13734 children to be included in the birthweight and childhood wheezing disorders analyses.

At the same time, a subcohort (BiB1000) of 1735 mothers and 1763 babies were also recruited for follow-up examinations. After excluding multiple births, preterm births and death before the age of 1 week, a total of 1598 children were included in growth pattern and wheezing disorder analyses.

\section{Data collection}

We have used five data sources: (1) hospital maternity records for information on birth weight, gestational age, gender of a child and number of live births; (2) BiB1000 cohort records for weight at $6,12,18,24$ and 36 months of age, that is, during the first, second, third, fourth and fifth visit after birth, respectively; (3) community health records for weight at 1 and 3 months of age; (4) baseline questionnaire data collected from the mothers on recruitment about their ethnicity, smoking and socioeconomic status (SES); and (5) linked primary care data about outcome variables (wheezing disorder diagnosis terms and treatment) recorded as Read Codes (http:// systems.hscic.gov.uk/data/uktc/readcodes).

\section{Case definition and ascertainment}

We drew up four disease definitions based on diagnostic codes and prescribed medication details entered by general practitioners onto the primary care database.

1. Asthma diagnosis: presence of asthma codes in the record;

2. Wheezing symptoms: presence of wheezing diagnosis codes in the record;

3. Wheezing disorder based on diagnosis (wheezing disorder diagnosis): presence of asthma or wheezing diagnosis codes in the record;

4. Wheezing disorder based on treatment (wheezing disorder treatment), existence of at least two drug prescriptions indicated for the treatment of asthma a minimum of 1 week and maximum of 12 months apart.

Drug and disease terms and codes used to confirm occurrences of wheezing disorders any time between 0 and 7 years of age are listed in online supplementary tables $\mathrm{S} 1$ and $\mathrm{S} 2$.

\section{Variables for analysis}

\section{Primary variables}

Where regression modelling was carried out, exposure variables were birth weight and growth; outcome variables were wheezing disorders (ie, asthma diagnosis, wheezing symptoms, wheezing disorders diagnosis and wheezing disorders treatment).

Two types of growth variables were used: age-based and visits-based. For the age-based growth, age of a child when the measurement of weight occurred was used as a time score. The data were collected through maternity records, BiB1000 questionnaire and the community health records, so the time points: $0,1,3,6,12,18,24$ and 36 months were used as time scores. In the visitsbased, however, only maternity records and the BiB1000 questionnaire data were considered. Therefore, $0,1,2$, 3,4 and 5 were used as times scores. Note that 0 stands for time when birth weight was measured (ie, birth), and $1,2,3,4$ and 5 represent $6,12,18,24$ and 36 months of BiB1000 questionnaires, respectively.

The aim of using the age-based and visits-based time scores was to explore the effects of growth in terms of latent growth factors (ie, intercept and slope) and weight status (ie, underweight, normal, overweight or obese based on the weight percentiles) at every visit, respectively. In the age-based approach, the age of the children at each time point needed to be identical or 
weight values were constrained to be missing if the recorded weight measurement did not reflect the time points. In the visits-based approach, however, the age of the children at each time point did not need to be identical and no constraint was imposed. The main difference between these two approaches was that in the age-based, group classification was based on how fast or slow the children grow as their age was identical or constrained to be identical. On the visits-based, however, although the group classification was similar to the agebased, the outputted intercept and slope were artificial and were not used to characterise how fast or slow the children grew between two times points as the age of children was not constrained to be identical. In addition, the age-based data had more missing value than the visits-based due to the constraint of age to be identical during the respective time points.

\section{Confounding variables}

Selection of variables was carried out based on the criteria that confounding variable must have an effect on the exposure and outcome variables, and should not be on the causal pathway. ${ }^{26-28}$ In order to minimise bias due to confounding and overadjustment, Direct Acyclic Graphs (DAGs) were used ${ }^{27} 29$ and models were tested using DAGitty software. ${ }^{28}$ Drawing a relationship between variables of interest (ie, confounding and main variables) was guided by epidemiological, biological and clinical knowledge. Online supplementary figures S1 and S2 illustrate the schematic view of adjustment and output for the list of 'minimally sufficient' confounding sets using DAGitty software.

In assessing the effect of birth weight on wheezing disorders, ethnicity, family asthma, gender, gestational age, maternal smoking, number of live births, parity and SES were selected as 'minimally sufficient' set of confounding variables. In assessing the effect of childhood growth on wheezing disorders, birth weight, ethnicity, family asthma, breast feeding, gender, maternal smoking, parity and SES were selected as 'minimally sufficient' set of confounding variables.

However, note that selection among sets of confounding variables was carried out retrospectively. Hence, availability of information on variables was also a factor during the selection process. As such, although the selected sets were better than the other candidate sets, no data were available for the variables 'family asthma' and 'breast feeding'.

\section{Missing data estimation variables}

Where imputations were carried out, missing data were estimated under Missing Data at Random (MAR) assumption that the missingness on outcome variables does not depend on the outcome variables themselves but can be explained by (or related to) other variables included in the imputation models (also known as auxiliary variables). ${ }^{30}$ The auxiliary variables included in the imputation process were: exposure variables, confounding variables and variables that can be related to the missingness. The first two types of variables were those included in the analysis models, whereas the third types of variables (maternal hypertension and diabetes) were included only in the imputation models.

A brief check on the variables before carrying out imputations showed that birth weight, gestational age and outcome variables (ie, asthma diagnosis, wheezing symptoms, wheezing disorder treatment and wheezing disorder diagnosis) were completely observed. To further explore if imputations were necessary or beneficial, dummy variables (ie, yes or no) were created as missing data indicator for each covariate with missing observations. When the missingness indicator variables and outcome variables were tested for correlations, the results consistently showed that there were no significant associations which also indicate that complete cases analysis could produce unbiased, albeit less precise, parameter estimates. $^{31}$ However, there were consistent significant associations between the missing indicator variables and other confounding variables which also suggest that imputations with inclusion of these covariates may improve the precision of the parameter estimates. $^{30} 31$

\section{Statistical analysis and software}

Birth weight was classified according to the Centre of Diseases Prevention and Control (CDC) $)^{32}$ and WHO methods $^{33}$ where $<2.5 \mathrm{~kg}=$ low, $2.5-4.0 \mathrm{~kg}=$ normal and $>4.0 \mathrm{~kg}=$ high. Age-specific and sex-specific SDS of weight were derived according to WHO growth standards ${ }^{34}$ in LMSgrowth Microsoft excel add-in software. ${ }^{35}$ The WHO growth standards population that we used to derive the SDS was made up of singleton term births. Hence, multiple and preterm births were excluded from the growth patterns and wheezing disorders analyses.

In identifying the best fitting growth patterns, growth mixture models (GMMs) were fitted, ${ }^{36} 37$ and in selecting the optimal number of classes and best growth model, we used model classification quality and model fit statistics. In addition, interpretability was also considered where we rejected models that consist of a class with $\leq 1 \%$ of the total population. When comparing growth patterns of children in our GMMs, we used WHO growth standards charts ${ }^{34}$ as a point of reference. In converting weight SDS into percentiles, we used a one-sided normal standard distribution. For example, weight SDS of -1.64 , $0,1.04$ and 1.64 are equivalent to the 5th, 50th, 85th and 95th centiles, respectively.

Missing data on covariates were estimated using Multiple Imputations by Chained Equation (MICE) models under MAR assumptions. ${ }^{38} 39$ In deciding how many data sets to be imputed, we took the number of imputations ( $n$ ) to be greater than the percentage or fraction of incomplete cases. ${ }^{38}$ Missing growth data were estimated using a Full Information Maximum Likelihood (FIML) method in which parameters are 
estimated using all available observations in the data set, under MAR assumption. ${ }^{41} 42$

GMM was carried out in Mplus V.7.11, and covariates' missing data estimation and regression modelling were carried out in Stata V.12. Five per cent significance levels and $95 \%$ CIs were adopted throughout.

\section{RESULTS}

\section{Birth weight and wheezing disorders}

The cohort was made up of 13734 children that yielded 74940 person years of follow-up. In total, $37.3 \%$ and $32.8 \%$ were Pakistani and white British origin, respectively; $12.6 \%$ were minority and $17.3 \%$ with missing ethnicity data. In total, $50.4 \%$ and $47.3 \%$ were male and female, respectively, and $2.3 \%$ of children had missing information on sex. In total, $82.6 \%, 9.1 \%$ and $8.3 \%$ of the cohort were 'normal', 'high' and 'low' birthweight children, respectively (table 1). Out of 13734 children, $6.1 \%$ were diagnosed as asthmatic, $14.5 \%$ had wheezing symptoms, $17.1 \%$ were either diagnosed for asthma or had wheezing symptoms, and $22.1 \%$ children were treated with asthma drugs based on primary care data available up to November 2014 (table 1).

\section{Low birth weight}

Low birth weight was associated with all four disease definitions. The adjusted relative risks (RRs) for 'asthma' diagnosis, 'wheezing' symptoms, 'wheezing disorder' diagnosis and 'wheezing disorder' treatment were 1.53 (95\% CI 1.20 to 1.96 ), 1.29 (95\% CI 1.10 to 1.52 ), 1.29 (95\% CI 1.12 to 1.50$)$ and 1.25 (95\% CI 1.10 to 1.42 ), respectively (table 2 ). The respective unadjusted RRs were 1.55 (95\% CI 1.27 to 1.89 ), 1.29 (95\% CI 1.13 to 1.46 ), 1.28 (95\% CI 1.14 to 1.45 ) and 1.27 (95\% CI 1.15 to 1.40$)$.

\section{High birth weight}

There was a consistent but weak evidence for a reduction of wheezing disorders risk for those children who were classified as being of high birth weight. The adjusted RRs for 'asthma' diagnosis, 'wheezing' symptoms, 'wheezing disorder' diagnosis and 'wheezing disorder' treatment were 0.95 (95\% CI 0.74 to 1.22 ), 0.90

Table 1 Characteristics of 13734 children with complete data on wheezing disorders and covariates

\begin{tabular}{|c|c|c|c|c|c|c|c|c|}
\hline & \multicolumn{2}{|c|}{ Asthma diagnosis } & \multicolumn{2}{|c|}{ Wheezing symptoms } & \multicolumn{2}{|c|}{$\begin{array}{l}\text { Wheezing disorder } \\
\text { diagnosis }\end{array}$} & \multicolumn{2}{|c|}{$\begin{array}{l}\text { Wheezing disorder } \\
\text { treatment }\end{array}$} \\
\hline & Yes/no & Yes (\%) & Yes/no & Yes (\%) & Yes/no & Yes (\%) & Yes/no & Yes (\%) \\
\hline \multicolumn{9}{|l|}{ Birth weight (kg) } \\
\hline Normal (2.5-4.0) & $668 / 10673$ & 5.9 & $1622 / 9719$ & 14.3 & $1907 / 9434$ & 16.8 & $2444 / 8897$ & 21.6 \\
\hline Low $(<2.5)$ & $104 / 1035$ & 9.1 & $209 / 930$ & 18.3 & $246 / 893$ & 21.6 & $311 / 828$ & 27.3 \\
\hline High (>4.0) & $69 / 1185$ & 5.5 & $163 / 1091$ & 13.0 & $194 / 1060$ & 15.5 & $280 / 974$ & 22.3 \\
\hline \multicolumn{9}{|l|}{ Ethnicity } \\
\hline White British & $217 / 4284$ & 4.8 & $586 / 3915$ & 13.1 & $706 / 3795$ & 15.7 & $1074 / 3427$ & 23.9 \\
\hline Pakistani & $382 / 4735$ & 7.5 & $857 / 4260$ & 16.7 & $985 / 4132$ & 19.2 & $1150 / 3967$ & 22.5 \\
\hline Others & $86 / 1647$ & 5.0 & $207 / 1526$ & 11.9 & $243 / 1490$ & 14.0 & $308 / 1425$ & 17.8 \\
\hline \multicolumn{9}{|l|}{ Gender } \\
\hline Male & $502 / 6415$ & 7.3 & $1220 / 5697$ & 17.6 & $1416 / 5501$ & 20.5 & $1775 / 5142$ & 25.7 \\
\hline Female & $318 / 6172$ & 4.9 & $742 / 5748$ & 11.4 & $890 / 5600$ & 13.7 & $1190 / 5300$ & 18.3 \\
\hline \multicolumn{9}{|l|}{ Gestational age } \\
\hline Term & $769 / 12100$ & 6.0 & $1841 / 11028$ & 14.3 & $2166 / 10703$ & 16.8 & $2792 / 10077$ & 21.7 \\
\hline Preterm & 72/793 & 8.3 & $153 / 712$ & 17.7 & $181 / 684$ & 20.9 & $243 / 622$ & 28.1 \\
\hline \multicolumn{9}{|l|}{ Number of births } \\
\hline Singleton & $803 / 12281$ & 6.1 & $1923 / 11161$ & 14.7 & 2262/10 822 & 17.3 & $2911 / 10173$ & 22.2 \\
\hline Twins & $17 / 297$ & 5.4 & $38 / 276$ & 12.1 & $43 / 271$ & 13.7 & $52 / 262$ & 16.6 \\
\hline Triplets & $0 / 9$ & 0 & $1 / 8$ & 11.1 & $1 / 8$ & 11.1 & $2 / 7$ & 22.2 \\
\hline \multicolumn{9}{|l|}{ Maternal smoking } \\
\hline No & $520 / 7371$ & 6.6 & $1162 / 6729$ & 14.7 & $1359 / 6532$ & 17.2 & $1710 / 6181$ & 21.7 \\
\hline Yes & $167 / 3295$ & 4.8 & $490 / 2972$ & 14.2 & $578 / 2884$ & 16.7 & $823 / 2639$ & 23.8 \\
\hline \multicolumn{9}{|l|}{ Parity } \\
\hline Primiparous & $292 / 4823$ & 5.7 & $686 / 4429$ & 13.4 & $821 / 4294$ & 16.1 & $1128 / 3987$ & 22.1 \\
\hline Multiparous & $489 / 7311$ & 6.3 & $1210 / 6590$ & 15.5 & $1401 / 6399$ & 18.0 & $1728 / 6072$ & 22.2 \\
\hline \multicolumn{9}{|c|}{ IMD 2010 quintile score } \\
\hline 1 & $487 / 7048$ & 6.5 & $1182 / 6353$ & 15.7 & $1372 / 6163$ & 18.2 & $1721 / 5814$ & 22.8 \\
\hline 2 & $115 / 1939$ & 5.6 & $253 / 1801$ & 12.3 & $304 / 1750$ & 14.8 & $435 / 1619$ & 21.2 \\
\hline 3 & $59 / 1196$ & 4.7 & $148 / 1107$ & 11.8 & $177 / 1078$ & 14.1 & $247 / 1008$ & 19.7 \\
\hline 4 & $18 / 317$ & 5.4 & $41 / 294$ & 12.2 & $53 / 282$ & 15.8 & $84 / 251$ & 25.1 \\
\hline 5 & $8 / 184$ & 4.2 & $30 / 162$ & 15.6 & $33 / 159$ & 17.2 & $49 / 143$ & 25.5 \\
\hline
\end{tabular}


Table 2 Adjusted relative risks and $95 \% \mathrm{Cls}$ of covariates using 40 imputed data sets

\begin{tabular}{|c|c|c|c|c|}
\hline & $\begin{array}{l}\text { Asthma } \\
\text { diagnosis }\end{array}$ & $\begin{array}{l}\text { Wheezing } \\
\text { symptoms }\end{array}$ & $\begin{array}{l}\text { Wheezing disorder } \\
\text { diagnosis }\end{array}$ & $\begin{array}{l}\text { Wheezing disorder } \\
\text { treatment }\end{array}$ \\
\hline \multicolumn{5}{|l|}{ Birth weight (kg) } \\
\hline Normal (2.5-4.0) & 1 & 1 & 1 & 1 \\
\hline High $(>4.0)$ & $0.95(0.75$ to 1.22$)$ & $0.90(0.77$ to 1.04$)$ & $0.91(0.79$ to 1.04$)$ & 0.99 (0.89 to1.11) \\
\hline Low $(<2.5)$ & 1.53 (1.20 to 1.96$)$ & 1.29 (1.10 to 1.52$)$ & $1.29(1.12$ to 1.50$)$ & 1.25 (1.10 to 1.42$)$ \\
\hline \multicolumn{5}{|l|}{ Ethnicity } \\
\hline White British & 1 & 1 & 1 & 1 \\
\hline Pakistani & 1.36 (1.11 to 1.66$)$ & $1.26(1.12$ to 1.42$)$ & $1.21(1.08$ to 1.35$)$ & $0.95(0.87$ to 1.05$)$ \\
\hline Others & $0.96(0.74$ to 1.25$)$ & $0.93(0.79$ to 1.08$)$ & $0.90(0.78$ to 1.04$)$ & $0.76(0.67$ to 0.85$)$ \\
\hline \multicolumn{5}{|l|}{ Gender } \\
\hline Male & 1 & 1 & 1 & 1 \\
\hline Female & 0.67 (0.58 to 0.76$)$ & $0.64(0.59$ to 0.70$)$ & $0.66(0.61$ to 0.72$)$ & $0.71(0.67$ to 0.76$)$ \\
\hline \multicolumn{5}{|l|}{ Gestational age } \\
\hline Term & 1 & 1 & 1 & 1 \\
\hline Preterm & $1.11(0.83$ to 1.48$)$ & $1.08(0.90$ to 1.30$)$ & $1.09(0.92$ to 1.29$)$ & $1.16(1.01$ to 1.34$)$ \\
\hline \multicolumn{5}{|l|}{ Number of births } \\
\hline Singleton & 1 & 1 & 1 & 1 \\
\hline Twins & $0.68(0.42$ to 1.10$)$ & $0.71(0.52$ to 0.97$)$ & $0.68(0.51$ to 0.90$)$ & $0.63(0.49$ to 0.81$)$ \\
\hline Triplets & - & 0.57 (0.09 to 3.60$)$ & 0.48 (0.08 to 3.03$)$ & $0.75(0.22$ to 2.56$)$ \\
\hline \multicolumn{5}{|l|}{ Maternal smoking } \\
\hline No & 1 & 1 & 1 & 1 \\
\hline Yes & $0.86(0.70$ to 1.05$)$ & $1.10(0.98$ to 1.24$)$ & 1.07 (0.97 to 1.19$)$ & $1.05(0.97$ to 1.15$)$ \\
\hline \multicolumn{5}{|l|}{ Parity } \\
\hline Primiparous & 1 & 1 & 1 & 1 \\
\hline Multiparous & $1.04(0.91$ to 1.20$)$ & 1.14 (1.04 to 1.24$)$ & $1.10(1.02$ to 1.19$)$ & $1.02(0.95$ to 1.08$)$ \\
\hline IMD 2010 quintile score & 0.96 (0.88 to 1.05$)$ & $0.95(0.90$ to 1.00$)$ & $0.95(0.91$ to 1.00$)$ & $0.97(0.93$ to 1.00$)$ \\
\hline
\end{tabular}

(95\% CI 0.77 to 1.04$), 0.91$ (95\% CI 0.79 to 1.04$)$ and 0.99 (95\% CI 0.89 to1.11), respectively (table 2). The respective unadjusted RRs of high birth weight for 'asthma' diagnosis, 'wheezing' symptoms, 'wheezing disorder' diagnosis and 'wheezing disorder' treatment were 0.93 (95\% CI 0.73 to 1.19$), 0.91$ (95\% CI 0.78 to 1.06$)$, 0.92 (95\% CI 0.80 to 1.05$)$ and 1.04 (95\% CI 0.93 to 1.16).

\section{Growth and wheezing disorders}

The BiB1000 follow-up cohort consisted of 1598 children that contributed a total of 8683 person years of follow-up. The total number of children who had 'asthma' diagnosis, 'wheezing' symptoms, 'wheezing disorders' diagnosis and 'wheezing disorders' treatment were $113(7.1 \%), 252(15.8 \%), 300(18.8 \%)$ and 369 $(23.1 \%)$, respectively, slightly higher than the whole $\mathrm{BiB}$ cohort. Fewer than $2 \%$ and $10 \%$ of the BiB1000 children were diagnosed with or treated for wheezing disorders during the first 3 months and the first 6 months, respectively (see online supplementary table S3).

\section{Age-based weight patterns}

According to the optimal number of class determination results, a four class model was best (see online supplementary table $\mathrm{S} 4$ ). However, a three class model was preferred on an interpretability basis (table 3 and online supplementary figure S3A). Class 1 (95.8\%) was composed of children whose mean birth weight was at the 46 th centile and were just over the 60th centile at the age of 1 year and stayed around 60th centile afterwards according to WHO growth standards. ${ }^{34}$ Class $2(2.2 \%)$ was composed of children whose mean weight at birth was on the 28th centile then increased to the 96th centile at 1 year of age and persisted to be overweight until the age of 3 . Class $3(2.0 \%)$ were a group of children whose mean birth weight was on the 29th centile, who subsequently showed very slow growth, their mean weight reaching the 3 rd centile at 1 year of age, followed by moderate acceleration to reach the 56th centile by the age of 3 . Class 1 , class 2 and class 3 could be characterised as 'normal', 'fast' and 'slow' growth groups, respectively. Online supplementary table S5 gives estimated means of the growth model parameters.

The adjusted RRs for 'asthma' diagnosis, 'wheezing' symptoms, 'wheezing disorder' diagnosis and 'wheezing disorders' treatment for fast growth group were 0.81 (95\% CI 0.12 to 5.46$), 1.59$ (95\% CI 0.67 to 3.71$), 1.30$ (95\% CI 0.56 to 3.06 ) and 0.77 (95\% CI 0.20 to 2.51 ), respectively, when compared with the 'normal' growth group (table 4). The adjusted RRs of the 'slow' as compared with the 'normal' growth group for 'wheezing' symptoms, 'wheezing disorder' diagnosis and 'wheezing disorders' treatment were 0.72 (95\% CI 0.20 to 2.62), 
Table 3 Estimated mean and percentiles of 1598 children by growth classes

\begin{tabular}{|c|c|c|c|}
\hline & \multicolumn{3}{|l|}{ Growth classes } \\
\hline & Class 1 & Class 2 & Class 3 \\
\hline \multicolumn{4}{|c|}{ Age-based weight SDS } \\
\hline Birth & 46th $(-0.11$ SDS) & 28th (-0.59 SDS) & 29th $(-0.56 \mathrm{SDS})$ \\
\hline 1 month & 43rd (-0.18 SDS) & 19th (-0.89 SDS) & 23rd (-0.75 SDS) \\
\hline 3 months & 38th (-0.31 SDS) & 7 th $(-1.48$ SDS $)$ & 13th $(-1.13 \mathrm{SDS})$ \\
\hline 6 months & 45th (-0.12 SDS) & 34th (-0.40 SDS) & 8th $(-1.39$ SDS) \\
\hline 12 months & 61 st (0.27 SDS) & 96th (1.75 SDS) & 3rd (-1.91 SDS) \\
\hline 18 months & 60th (0.25 SDS) & 94th (1.57 SDS) & 8th (-1.40 SDS) \\
\hline 24 months & 59th (0.23 SDS) & 92nd (1.39 SDS) & 19th $(-0.88 \mathrm{SDS})$ \\
\hline 36 months & 58th (0.20 SDS) & 85th (1.02 SDS) & 56th (0.14 SDS) \\
\hline \multicolumn{4}{|c|}{ Visits-based weight SDS } \\
\hline Birth & 47th (-0.08 SDS) & 40th (-0.26 SDS) & - \\
\hline 1st visit & 53rd (0.04 SDS) & 56th (0.16 SDS) & - \\
\hline 2nd visit & 55th (0.13 SDS) & 71rd (0.54 SDS) & - \\
\hline 3rd visit & 57th (0.18 SDS) & 81st (0.89 SDS) & - \\
\hline 4th visit & 57th (0.19 SDS) & 88th (1.20 SDS) & - \\
\hline 5th visit & 53rd (0.09 SDS) & 96th (1.70 SDS) & - \\
\hline
\end{tabular}

0.60 (95\% CI 0.16 to 1.95$)$ and 0.81 (95\% CI 0.29 to $2.25)$, respectively. The respective unadjusted RRs for both growth groups remained similar (table 4).

\section{Visits-based growth patterns}

The age ranges of the children during their first, second, third, fourth and fifth visits after birth were $4.9-9.4, \quad 10.7-18.3, \quad 15.2-22.8, \quad 23.4-28.5$ and 35.4-40.6 months, respectively. Although the determination of the optimal number of classes favoured a model with four classes, the two class model was selected on a model interpretability basis (see online supplementary table S4). Class $1(92.7 \%)$ comprised those children who were around the 46th centile at birth and 52nd centile during the first visit after birth and remained around the 60th centile during the next four visits according to the WHO growth standards chart ${ }^{34}$; class 2 $(7.3 \%)$ comprised children who were, on average, at the 29th centile at birth and 57th centile during the first visit after birth then consistently accelerated to reach the 95th centile during the last visit (see online supplementary figure S3B and table 3). Class 1 and class 2 could be characterised as 'inconsistent' and 'consistent' growth groups, respectively.

The adjusted RRs for 'asthma' diagnosis, 'wheezing' symptoms, 'wheezing disorder' diagnosis and 'wheezing disorders' treatment for the 'inconsistent' growth group were 1.47 (95\% CI 0.71 to 3.01$), 1.13$ (95\% CI 0.66 to $1.95), 1.38$ (95\% CI 0.90 to 2.12 ) and 1.17 (95\% CI 0.76 to 1.81$)$, respectively, when compared with the 'consistent' growth group. The respective unadjusted RRs remained similar (table 5 ).

\section{Complete cases versus imputed data set results}

The complete cases analysis for birth weight and wheezing disorders retained 10623 out of 13734 children.
The complete case analyses for weight growth patterns based on age and visits retained 1572 of the 1598 children. The results of complete case analyses were very close to the imputed data analyses as expected given that all the outcome variables were completely observed and the missing indicator variables for the incomplete covariates did not have strong relationship with the outcome variables (see online supplementary tables S6 and S7).

\section{DISCUSSION}

In this prospective cohort study, we found that low birth weight was strongly associated with wheezing disorders and there was consistent, albeit weak, evidence that high birth weight was associated with reduced risk of wheezing disorders during the preschool period. Our findings for the effects of low birth weight on wheezing disorder diagnosis and treatment are in line with the findings of our recent meta-analysis and systematic review, showing a $37 \%$ increase in wheezing disorders risk for low birth weight $(\mathrm{OR}=1.37 ; 95 \%$ CI 1.05 to 1.79$)$ compared with normal birth weight, ${ }^{10}$ although the results here are slightly attenuated due to our use of RR as a measure of association. However, our finding of the effect of high birth weight on wheezing disorders is slightly different to that of the reported $\mathrm{OR}$ in the meta-analysis ( $\mathrm{OR}=1.02 ; 95 \%$ CI 0.99 to 1.04 ) with both wheezing disorders diagnosis and treatment showing that there was a non-significant reduction of risk.

Analysis of our age-based weight growth patterns have shown inconsistent results for the group classified as 'fast' growth group. While there was a weak evidence for an increased risk of wheezing disorders according to diagnosis, there was a weak evidence for a reduced risk of wheezing disorders treatment (table 5). However, the 
Table 4 Characteristics of 1598 children with complete data on wheezing disorders and covariates

\begin{tabular}{|c|c|c|c|c|c|c|c|c|}
\hline & \multicolumn{2}{|c|}{ Asthma diagnosis } & \multicolumn{2}{|c|}{$\begin{array}{l}\text { Wheezing } \\
\text { symptoms }\end{array}$} & \multicolumn{2}{|c|}{$\begin{array}{l}\text { Wheezing disorder } \\
\text { diagnosis }\end{array}$} & \multicolumn{2}{|c|}{$\begin{array}{l}\text { Wheezing disorder } \\
\text { treatment }\end{array}$} \\
\hline & Yes/no & Yes (\%) & Yes/no & Yes (\%) & Yes/no & Yes (\%) & Yes/no & Yes (\%) \\
\hline \multicolumn{9}{|l|}{ Birth weight (kg) } \\
\hline Normal (2.5-4.0) & $101 / 1314$ & 7.1 & $221 / 1194$ & 15.6 & $264 / 1151$ & 18.7 & $321 / 1094$ & 22.7 \\
\hline Low $(<2.5)$ & $6 / 64$ & 8.6 & $14 / 56$ & 20.0 & $16 / 54$ & 22.9 & $20 / 50$ & 28.6 \\
\hline High (>4.0) & $6 / 107$ & 5.3 & $17 / 96$ & 15.0 & $20 / 93$ & 17.7 & $28 / 85$ & 24.8 \\
\hline \multicolumn{9}{|l|}{ Ethnicity } \\
\hline White British & $24 / 578$ & 4.0 & $82 / 520$ & 13.6 & $95 / 507$ & 15.8 & $141 / 461$ & 23.4 \\
\hline Pakistani & $73 / 689$ & 9.6 & $134 / 628$ & 17.6 & $164 / 598$ & 21.5 & $175 / 587$ & 23.0 \\
\hline Others & $16 / 216$ & 6.9 & $36 / 196$ & 15.5 & $41 / 191$ & 17.7 & $53 / 179$ & 22.8 \\
\hline \multicolumn{9}{|l|}{ Gender } \\
\hline Male & $70 / 708$ & 9.0 & $159 / 619$ & 20.4 & $185 / 593$ & 23.8 & $212 / 566$ & 27.2 \\
\hline Female & $43 / 777$ & 5.2 & $93 / 727$ & 11.3 & $115 / 705$ & 14.0 & $157 / 663$ & 19.1 \\
\hline \multicolumn{9}{|l|}{ Maternal smoking } \\
\hline No & $90 / 1051$ & 7.9 & $177 / 964$ & 15.5 & $213 / 928$ & 18.7 & $256 / 885$ & 22.4 \\
\hline Yes & $23 / 433$ & 5.0 & $74 / 382$ & 16.2 & $86 / 370$ & 18.9 & $112 / 344$ & 24.6 \\
\hline \multicolumn{9}{|l|}{ Parity } \\
\hline Primiparous & $41 / 571$ & 6.7 & $87 / 525$ & 14.2 & $106 / 506$ & 17.3 & $144 / 468$ & 23.5 \\
\hline Multiparous & $70 / 892$ & 7.3 & $163 / 799$ & 16.9 & $191 / 771$ & 19.9 & $218 / 744$ & 22.7 \\
\hline \multicolumn{9}{|c|}{ IMD 2010 quintile score } \\
\hline 1 & $83 / 998$ & 7.7 & 183/898 & 16.9 & $217 / 864$ & 20.1 & $255 / 826$ & 23.6 \\
\hline 2 & $19 / 271$ & 6.6 & $37 / 253$ & 12.8 & $45 / 245$ & 15.5 & $64 / 226$ & 22.1 \\
\hline 3 & $10 / 158$ & 6.0 & $23 / 145$ & 13.7 & $28 / 140$ & 16.7 & $36 / 132$ & 21.4 \\
\hline 4 & $1 / 34$ & 2.9 & 3/32 & 8.6 & $4 / 31$ & 11.4 & $6 / 29$ & 17.1 \\
\hline 5 & $0 / 24$ & 0 & $6 / 18$ & 25.0 & $6 / 18$ & 25.0 & $8 / 16$ & 33.3 \\
\hline
\end{tabular}

IMD, index of multiple deprivation.

results showed that the 'slow' growth group did have a reduced risk for both wheezing disorders diagnosis and treatment, albeit weak evidence, when compared with the 'normal' growth group (table 5). Furthermore, in our attempt to further analyse the effects of visits-based weight SDS on wheezing disorders, there was a weak evidence for an increase risk of wheezing disorders diagnosis and treatment for the group of children who grew 'inconsistently' and were seen to be obese by the last visit.

Table 5 Adjusted and unadjusted RRs and 95\% Cl for growth patterns and wheezing disorders in the BiB1000 cohort

\begin{tabular}{lll}
\hline & Unadjusted RR (95\% Cl; p Value) & Adjusted RR (95\% Cl; p Value) \\
\hline Age-based weight SDS & & $0.81(0.12$ to $5.46 ; 0.83)$ \\
Class 2 (fast growth) & $0.82(0.12$ to $5.56 ; 0.84)$ & $1.59(0.68$ to $3.71 ; 0.29)$ \\
Asthma diagnosis & $1.50(0.62$ to $3.56 ; 0.36)$ & $1.30(0.56$ to $3.06 ; 0.54)$ \\
Wheezing symptom & $1.25(0.53$ to $2.97 ; 0.61)$ & $0.77(0.28$ to $2.17 ; 0.63)$ \\
Wheezing disorder diagnosis & $0.76(0.27$ to $2.14 ; 0.60)$ & 1 \\
Wheezing disorder treatment & & $0.72(0.20$ to $2.63 ; 0.29)$ \\
Class 3 (slow growth) & 1 & $0.60(0.16$ to $2.18 ; 0.44)$ \\
Asthma diagnosis & $0.80(0.21$ to $2.93 ; 0.73)$ & $0.81(0.29$ to $2.25 ; 0.69)$ \\
Wheezing symptom & $0.67(0.18$ to $2.45 ; 0.54)$ & $1.47(0.71$ to $3.01 ; 0.30)$ \\
Wheezing disorder diagnosis & $0.81(0.29$ to $2.25 ; 0.68)$ & $1.13(0.66$ to $1.95 ; 0.65)$ \\
Wheezing disorder treatment & & $1.38(0.90$ to $2.12 ; 0.14)$ \\
Visits-based weight SDS & & $1.17(0.76$ to $1.81 ; 0.47)$ \\
Class 2 (inconsistent growth) & $1.66(0.81$ to $3.42 ; 0.17)$ & \\
Asthma diagnosis & $1.15(0.66$ to $1.99 ; 0.62)$ & \\
Wheezing symptom & $1.42(0.92$ to $2.19 ; 0.11)$ & \\
Wheezing disorder diagnosis & $1.14(0.74$ to $1.76 ; 0.55)$ & \\
Wheezing disorder treatment & &
\end{tabular}


The findings of the effects of growth on wheezing disorders analyses may not be directly comparable with the previous studies ${ }^{7} 11 \quad 13 \quad 14 \quad 16 \quad 17 \quad 19-23$ as they assumed a homogeneous growth among the respective study population and investigated the effect of overall mean change on wheezing disorders. However, Rzehak et $a l^{18}$ who used GMM reported HRs of 1.22 (95\% CI 1.08 to 1.39) and 1.43 (95\% CI 0.90 to 2.27) for groups of children exhibited rapid growth only until 2 years and persistent rapid growth, respectively. The authors' growth pattern and risk estimates were similar to our age-based fast growth group and visits-based inconsistent growth group, respectively. Another two studies that investigated the effects of weight status changes at different age points reported an insignificant increase in wheezing disorders risk which are similar to our 'inconsistent growth' groups of the 'visits-based' growth pattern risk estimates. ${ }^{12} 15$

In our previous meta-analyses and systematic reviews, we found that low birth weight and high body mass index (BMI) were associated with wheezing disorders. ${ }^{10} 43$ However, we also acknowledged that it may not be apparent whether high BMI is causing wheezing disorders or otherwise from the findings. This is because children with wheezing disorders may become less active which can lead to obesity or obese children may experience wheezing symptoms due to narrowing of airways. In our growth patterns and wheezing disorders analyses, we noted that, on average, the children with lower birthweight SDS showed significant growth changes during the first 6 months and were more likely to have experienced wheezing disorder conditions (tables 3 and 5). We also noted that children with the lowest birthweight SDS were more likely to be obese and to have experienced wheezing disorder conditions (tables 3 and 5). Given that a very small proportion of wheezing disorders or treatment cases were identified in the first 3 and 6 months (see online supplementary table S3), during which changes in growth occurred, it may strongly suggest that low birth weight coupled with rapid change in growth during the first 6 months is a risk factor for wheezing disorders. The temporal relationship between obesity and wheezing disorders in this study remains difficult to disentangle; however, in a recent Mendelian randomisation study by Granell et $a l,{ }^{44}$ it has been reported that obesity precedes childhood wheezing disorders.

Our work has certain weakness, so that the results need to be interpreted carefully. First, although the sample size for birth weight and wheezing disorders was sufficiently large, study participants were those who were born at a single centre: the Bradford Royal Infirmary (BRI) maternity hospital. Births in the regional tertiary centre, home births and births in smaller hospitals outside Bradford would have been excluded. Second, participation in the subcohort (BiB1000) of growth patterns was mainly driven by the mothers' willingness to participate, and so there is likely to be selection bias. Third, some of the classes identified by our GMM contained a small proportion of children that resulted in having less precise risk estimates. Fourth, missing levels of growth data at some ages and visits was substantial, although we applied missing data handling techniques to address this limitation. Fifth, information on family asthma and breast feeding was missing, so our models were not adjusted for these potential confounding variables. However, the lack of adjustment may not have had a drastic effect on our birthweight risk estimates as there was no difference between the studies that adjusted for family asthma and those did not. ${ }^{10}$ Likewise, Rzehak et $a l^{18}$ also reported that there was no significant difference between unadjusted and adjusted (ie, for breast feeding and family asthma) model results.

Nonetheless, there are particular strengths of our analysis. First, in our birthweight and wheezing disorders analyses, our sample size was reasonably large. Second, we were able to implement techniques to reduce potential bias due to confounding variables such as the use of DAGs to inform the modelling process. Third, we were able to implement missing data techniques to minimise bias and presented both the complete cases and imputed data sets results to give more insight. Fourth, although we had small size for growth pattern analysis, we are able to implement advanced statistical techniques to account for potential heterogeneity of growth between and within groups. Finally, we were also able to use age-specific and sex-specific standardised weight scores which have the advantage of clearly depicting the growth patterns of children in comparison to the standard growth reference. ${ }^{34}$ The standard scores are convertible to percentiles ${ }^{35}$ which can then be compared with the growth charts used by clinicians or growth monitoring workers in their daily practice.

In conclusion, in this large prospective cohort data analysis, we have confirmed that low birthweight children have a moderate associated risk of wheezing disorders whereas high birthweight children have a non-significant reduced risk. There is a weak evidence that suggests 'fast' or 'inconsistent' growth predispose to wheezing disorders, and 'slow' growth reduces the risk which needs further investigation using larger data sets. However, the results may indicate that maintaining optimal prenatal and postnatal growths reduce a risk of childhood wheezing disorders.

Acknowledgements Born in Bradford is only possible because of the enthusiasm and commitment of the Children and Parents in BiB. The authors are grateful to all the participants, health professionals and researchers who have made Born in Bradford happen.

Contributors TFM, RGF and RCP conceived the idea. TFM performed all the statistical analyses, interpretation of results and drafted the manuscript. RGF and RCP revised and commented on the manuscript. All authors approved the final version of the manuscript.

Funding TFM is funded by the Hall Dorman Research PhD Scholarship. Data collection was funded by the National Institute for Health Research (NIHR) under the Collaborations for Leadership in Applied Health Research and Care (CLAHRC) programme for Leeds, York and Bradford and the Programme Grants for Applied Research funding scheme. 
Competing interests None declared.

Ethics approval Ethics approval was granted to the Born in Bradford project by Bradford Research Ethics Committee (Ref 07/H1302/112).

Provenance and peer review Not commissioned; externally peer reviewed.

Data sharing statement No additional data are available.

Open Access This is an Open Access article distributed in accordance with the Creative Commons Attribution Non Commercial (CC BY-NC 4.0) license, which permits others to distribute, remix, adapt, build upon this work noncommercially, and license their derivative works on different terms, provided the original work is properly cited and the use is non-commercial. See: http:// creativecommons.org/licenses/by-nc/4.0/

\section{REFERENCES}

1. Roche R, Jeffery R. Remodelling and inflammation. In: Silverman M, ed. Childhood asthma and other wheezing disorders. 2nd edn. Great Britain: Arnold, 2002:93-105.

2. World Health Organization (WHO). Asthma Fact Sheet Number 307. 2013. http://www.who.int/mediacentre/factsheets/fs307/en/ (accessed 20 Feb 2015).

3. Masoli M, Fabian D, Holt S, et al. The global burden of asthma: executive summary of the GINA Dissemination Committee Report. Allergy 2004;59:469-78.

4. Bateman ED, Hurd SS, Barnes PJ, et al. Global strategy for asthma management and prevention: GINA executive summary. Eur Respir $J$ 2008;31:143-78.

5. Bush A, Fleming $L$. Diagnosis and management of asthma in children. BMJ 2015;350:h996.

6. Brand PL, Baraldi E, Bisgaard $\mathrm{H}$, et al. Definition, assessment and treatment of wheezing disorders in preschool children: an evidence-based approach. Eur Respir J 2008;32:1096-110.

7. Pike KC, Crozier SR, Lucas JS, et al. Patterns of fetal and infant growth are related to atopy and wheezing disorders at age 3 years. Thorax 2010;65:1099-106.

8. Been JV, Lugtenberg MJ, Smets E, et al. Preterm birth and childhood wheezing disorders: a systematic review and meta-analysis. PLoS Med 2014;11:e1001596.

9. Rothenbacher D, Weyermann M, Fantuzzi G, et al. Adipokines in cord blood and risk of wheezing disorders within the first two years of life. Clin Exp Allergy 2007;37:1143-9.

10. Mebrahtu TF, Feltbower RG, Greenwood DC, et al. Birth weight and childhood wheezing disorders: a systematic review and meta-analysis. J Epidemiol Community Health 2015;69:500-8.

11. Mamun AA, Lawlor DA, Alati R, et al. Increasing body mass index from age 5 to 14 years predicts asthma among adolescents: evidence from a birth cohort study. Int J Obes 2007;31:578-83.

12. Scholtens $\mathrm{S}$, Wijga $\mathrm{AH}$, Seidell JC, et al. Overweight and changes in weight status during childhood in relation to asthma symptoms at 8 years of age. J Allergy Clin Immunol 2009;123:1312-18.e2.

13. Zhang Z, Lai HJ, Roberg KA, et al. Early childhood weight status in relation to asthma development in high-risk children. J Allergy Clin Immunol 2010;126:1157-62.

14. Flexeder $\mathrm{C}$, Thiering $\mathrm{E}$, Brüske I, et al. Growth velocity during infancy and onset of asthma in school-aged children. Allergy 2012;67:257-64.

15. Magnusson JO, Kull I, Mai XM, et al. Early childhood overweight and asthma and allergic sensitization at 8 years of age. Pediatrics 2012;129:70-6.

16. van der Gugten AC, Koopman M, Evelein AM, et al. Rapid early weight gain is associated with wheeze and reduced lung function in childhood. Eur Respir J 2012;39:403-10.

17. Anderson EL, Fraser A, Martin RM, et al. Associations of postnatal growth with asthma and atopy: the PROBIT Study. Pediatr Allergy Immunol 2013;24:122-30.

18. Rzehak $\mathrm{P}$, Wijga $\mathrm{AH}$, Keil $\mathrm{T}$, et al. Body mass index trajectory classes and incident asthma in childhood: results from 8 European Birth Cohorts-a Global Allergy and Asthma European Network initiative. J Allergy Clin Immunol 2013;131:1528-36.

19. Sonnenschein-van der Voort AM, Howe LD, Granell R, et al. Influence of childhood growth on asthma and lung function in adolescence. J Allergy Clin Immunol 2015;135: 1435-43.e7.

20. Magnus MC, Stigum $\mathrm{H}$, Håberg SE, et al. Peak weight and height velocity to age 36 months and asthma development: the Norwegian mother and child cohort study. PLOS ONE 2015;10:e0116362.
21. Mai XM, Gäddlin PO, Nilsson L, et al. Early rapid weight gain and current overweight in relation to asthma in adolescents born with very low birth weight. Pediatr Allergy Immunol 2005;16:380-5.

22. Sonnenschein-van der Voort AM, Jaddoe VW, Raat $\mathrm{H}$, et al. Fetal and infant growth and asthma symptoms in preschool children: the Generation R Study. Am J Respir Crit Care Med 2012;185:731-7.

23. de Korte-de Boer D, Mommers M, Thijs C, et al. Early life growth and the development of preschool wheeze, independent from overweight: the LucKi Birth Cohort Study. J Pediatr 2015; 166:343-9.e1.

24. Wright J, Small N, Raynor P, et al. Cohort profile: the Born in Bradford multi-ethnic family cohort study. Int $J$ Epidemiol 2013;42:978-91.

25. Raynor P, Group BiBC. Born in Bradford, a cohort study of babies born in Bradford, and their parents: protocol for the recruitment phase. BMC Public Health 2008;8:327.

26. Tu YK, West R, Ellison GT, et al. Why evidence for the fetal origins of adult disease might be a statistical artifact: the "reversal paradox" for the relation between birth weight and blood pressure in later life. Am J Epidemiol 2005;161:27-32.

27. Greenland S, Pearl J, Robins JM. Causal diagrams for epidemiologic research. Epidemiology 1999;10:37-48

28. Textor J, Hardt J, Knüppel S. DAGitty: a graphical tool for analyzing causal diagrams. Epidemiology 2011;22:745.

29. Schisterman EF, Cole SR, Platt RW. Overadjustment bias and unnecessary adjustment in epidemiologic studies. Epidemilogy 2009;20:488-95.

30. Collins LM, Schafer JL, Kam CM. A comparison of inclusive and restrictive strategies in modern missing data procedures. Psychol Methods 2001;6:330.

31. Sterne JA, White IR, Carlin JB, et al. Multiple imputation for missing data in epidemiological and clinical research: potential and pitfalls. BMJ 2009;338:b2393.

32. Center for Diseases prevention and Control (CDC). Pediatric and Pregnancy Nutrition Surveillance System: PedNSS Health Indicators. 2009. http://www.cdc.gov/pednss/what_is/pednss_health_ indicators.htm (accessed 04 Feb 2015).

33. World Health Organization (WHO). International Statistical Classification of Diseases and Related Health Problems 10th Revision (ICD-10)-2014-WHO Version for 2014: disorders related to length of gestation and fetal growth (P05-P08). 2014. http://apps. who.int/classifications/icd10/browse/2014/en\#/P05-P08 (accessed 03 Feb 2015).

34. World Health Organization (WHO). WHO Child Growth Standards: methods and development: length/height-for-age, weight-for-age, weight-for-length, weight-for-height and body mass index-for-age. Child growth standards. 2006. http://www.who.int/childgrowth/publications/ technical_report_pub/en/index.html (accessed 4 Feb 2015).

35. Pan H, Cole T. LMSgrowth, a Microsoft Excel add-in to access growth references based on the LMS method. Version 2.77. 2012. http://www.healthforallchildren.com/?product=Imsgrowth (accessed 20 Feb 2015).

36. Duncan TE, Duncan SC, Strycker LA. Growth mixture modeling. In: Marcoulides G, ed. An introduction to Latent Growth Curve Modeling. 2nd edn. Lawrence Erlbaum Associates, 2006:125-49.

37. Muthén $B$. Latent variable analysis: growth mixture modeling and related techniques for longitudinal data. In: Kaplan BA, ed. The handbook of quantitative methodology for the social sciences. Thousand Oaks, CA: Sage Publications, 2004:345-68.

38. Royston $P$, White IR. Multiple imputation by chained equations (MICE): implementation in Stata. J Stat Software 2011;45:1-20

39. White IR, Royston P, Wood AM. Multiple imputation using chained equations: issues and guidance for practice. Stat Med 2011;30:377-99.

40. Graham JW, Olchowski AE, Gilreath TD. How many imputations are really needed? Some practical clarifications of multiple imputation theory. Prev Sci 2007;8:206-13.

41. Schafer JL, Graham JW. Missing data: our view of the state of the art. Psychol Methods 2002;7:147-77.

42. Enders CK, Bandalos DL. The relative performance of full information maximum likelihood estimation for missing data in structural equation models. Struct Equation Model 2001; 8:430-57.

43. Mebrahtu TF, Feltbower RG, Greenwood DC, et al. Childhood body mass index and wheezing disorders: a systematic review and meta-analysis. Pediatr Allergy Immunol 2015;26:62-72.

44. Granell R, Henderson AJ, Evans DM, et al. Effects of BMI, fat mass, and lean mass on asthma in childhood: a Mendelian randomization study. PLoS Med 2014;11:e1001669. 